\title{
Descriptors Derived From Feedback on Teaching Mathematics in School
}

\author{
Gasanguseyn I. Ibragimov ${ }^{1}$, Aliya A. Kalimullina ${ }^{1 *}$ \\ ${ }^{1}$ Institute of Psychology and Education, Kazan (Volga region) Federal University, Kazan, RUSSIA
}

Received 4 March 2021 - Accepted 2 June 2021

\begin{abstract}
The purpose of this article was to identify the mechanism of bilateral feedback on Mathematics homework and to determine its impact on the success of schoolchildren learning. The following were used as the main research methods: the study and generalization of pedagogical experience which helped to consider possible ways of providing feedback on homework in Mathematics; the analysis of student artefacts with subsequent statistical processing. The latter made it possible to study the dynamics of students' knowledge of Mathematics and to judge the effectiveness of feedback on homework. The article reveals possible ways to provide feedback on homework in Mathematics deploying digital technologies; a scheme for meaningful feedback and ensuring its bilateral nature has been developed; the influence of the feedback in question on learning success was calculated. The implications of the study involve the fact that the developed didactic conditions ensure a bilateral nature of feedback during self-directed learning of Mathematics using digital technologies. This, in turn, contributes to the efficiency of the educational process and the provision of visible learning.
\end{abstract}

Keywords: feedback, homework, effect size, bilateral nature of feedback, visible learning, feedback scheme

\section{INTRODUCTION}

In the modern educational process, there is a general trend towards a stronger role of feedback. The value of the lesson expressed in the development of subject, meta-subject and personal competencies of schoolchildren, largely depends on the quality of feedback arrangements in the lesson. It is especially important to organize feedback while studying mathematics, since, according to many students, this subject is the most difficult.

In addition, according to the federal state educational standard of compulsory education, a modern schoolchild should be able to independently determine goals and draw up a plan for their activities, as well as implement, monitor and correct them (Federal State Educational Standard for Compulsory Education, 2010). However, the analysis of an actual school practice shows that quite so often the student blindly follows what the teacher says, without self-regulation of their actions: selfcontrol, self-assessment, reflection and self-study. Meanwhile, according to the researchers, it is the visible learning activity that improves the academic results of schoolchildren (Hattie, 2017), and goal-setting is 'central to the activities and formation of new human actions' (Ibragimov, 2017). Hattie (2017) writes that the most important thing is to make teaching visible to the student and leaching to the teacher. The more a student becomes a teacher and a teacher becomes a student, the more success they will achieve. One of the main conditions for creating such an educational environment is the availability of and demand for feedback.

The most common feedback tool is control. Most often, control in Mathematics lessons is carried out through quizzes, surveys, as well as through self-guided work and examination tests. However, all these means are predominantly one-way - from the student to the teacher. Moreover, the techniques implemented in practice do not completely cover all feedback issues, i.e. they do not provide participants of the educational process (teacher and students) with immediate information about the goals of learning, about the course and results of learning in the lesson, its milestones, as well as about further actions to achieve the goal (Zaitseva et al., 2018). In addition, feedback is often only result-oriented, but not process-oriented, and the

(c) 2021 by the authors; licensee Modestum. This article is an open access article distributed under the terms and conditions of the Creative Commons Attribution License (http://creativecommons.org/licenses/by/4.0/).

guseinibragimov@yandex.ru $₫$ kalimullina-aliya@yandex.ru (*Correspondence) 


\section{Contribution to the literature}

- The article reveals possible ways to provide feedback on homework in Mathematics deploying digital technologies;

- a scheme for meaningful feedback and ensuring its bilateral nature has been developed;

- the influence of the feedback in question on learning success was calculated;

- the developed didactic conditions ensure a bilateral nature of feedback during self-directed learning of Mathematics using digital technologies.

assessment obtained as a result of control does not carry any data and does not allow us to see changes in educational results.

However, the quantity and quality of feedback is an important correlator of student success. Therefore, it is necessary to find such feedback mechanisms that would allow students to see the process of their learning, and teachers - the process of their teaching, i.e., would make learning and teaching visible. The need for such feedback has become even more pressing during the pandemic when the educational process was forced to be carried out remotely. In these conditions, it became obvious that without correct and objective bilateral feedback it is impossible to ensure the quality of the educational process. It is especially difficult to do that when studying Mathematics, which does not lend itself to a self-study by schoolchildren. Hence the problem: what are the feedback mechanisms that would make learning open to all participants in the educational process?

The study of literature on Psychology and Education shows that the research of both home and foreign scientists is devoted to various aspects of feedback in the lesson.

Researchers define 'feedback' as 'a tool that gives an idea of how the learning process is undergoing, informs the teacher of the achievements and problems of students, allowing you to determine the level of goal achievement and solution of educational problems' (Begishev et al., 2021; Larionova et al., 2018; Myshkovskaya, 2016). However, there is a slightly different idea of feedback, which involves obtaining information from a teacher by students. This is exactly how Hattie (2017) interprets feedback as information provided by an agent (which can be a teacher, classmate, parent, as well as a book or personal experience) and related to aspects of activity or understanding. To indicate the feedback that learners receive, Korenev (2018) suggests using the term 'pedagogical feedback', and for the feedback that students report - 'academic feedback'. Also, Korenev (2018) proposed a typology of pedagogical feedback according to various classifying criteria, for example, according to the conditions for providing feedback, to the feedback form, to time, to volume, etc. (Korenev, 2018). The research emphasizes that feedback is a key element and one of the leading principles in the learning process, which quality plays an important role in achieving the planned learning outcomes (Salomasov, 2011). The conditions under which feedback provides students with the information that allows them to bridge the gap between the current and the desired result were identified (Baisalbaeva \& Syzdykova, 2019; Razumovskaya et al., 2018). Certain studies offer specific methods of organizing feedback in a training session (Gin, 2016; Korotkova \& Litvinovskaya, 2019).

This problem is also of interest to foreign researchers, who studied this problem on the example of various subjects (Foreign language, Native language, Biology, Mathematics). Thus, Wang and Li (2021) showed in their research that the most preferred type of feedback while studying English as a second language in the United States and English as a foreign language (EFL) in China in higher education is repetition (2021). Azizi et al. (2020) investigated self-assessment and peer feedback as two useful strategies to improve teaching and learning in language classes and evaluated their impact on speaking skills of EFL students. The results of this study show that both methods are useful in various aspects of enhancing speaking skills. Roslan et al. (2018) analyzed the use of feedback by a primary school teacher using Life Cycle lessons in a 5th grade bilingual Brunei Science classroom. The analysis showed that the teacher made use of only low-level questions and the feedback provided to the students was mainly to accept the students' answers, rather than challenge their ideas. Monteiro et al. (2019) analyzed the directedness of feedback in Mathematics lessons in elementary school through the lesson goal and the type of interaction; the type of question and answer of the student; the gender and student achievement. A study by $\mathrm{Hu}$ et al. (2021) examined Maths class feedback strategies used by 69 Chinese preschool teachers. The results showed that teachers are quite familiar with the use of feedback strategies such as approval, exchange of opinions, and teacher persistence. However, in terms of developing children's critical thinking, teachers were ineffective in interviewing and engaging with children.

The analysis shows that, despite the existing scientific groundwork, the studies do not present specific handson mechanisms for providing effective bilateral feedback in the educational process, on homework in Mathematics included. Moreover, all measurements of the effectiveness of various feedback methods were 
obtained abroad and require experimental verification in the context of a Russian school.

In this regard, the purpose of this study is to find a bilateral feedback mechanism for homework in Mathematics and to determine its impact on the success of schoolchildren's learning. The following were identified as the main goals: 1) to determine the ways of providing feedback on homework in Mathematics using digital technologies; 2) develop a scheme for providing meaningful feedback ensuring its bilateral nature; 3) to reveal the effectiveness of the influence of feedback on homework on the success of learning.

A review of ways to provide feedback using digital technologies on homework in Mathematics will reveal some imperfections of the feedback system implemented in the educational process, as well as identify the currently most appropriate way of providing meaningful formative feedback. The developed mechanism for providing feedback through the exchange of messages will ensure a bilateral nature of feedback during home self-study, and the developed scheme for providing meaningful feedback will help make learning visible to the student and can possibly be adopted as a useful tool by the teacher.

Thus, the implications of the study involve the fact that the developed didactic conditions ensure a bilateral nature of feedback during self-directed learning of Mathematics using digital technologies, and timely improvement of the educational process. This, in turn, contributes to the efficiency of the educational process and the provision of visible learning.

\section{RESEARCH METHODOLOGY}

The research and trial facilities of the study was a boarding school of general education 'Lyceum named after N.I. Lobachevsky' of Federal State Autonomous Educational Institution of Higher Education Kazan (Volga Region) Federal University “. The choice of the facilities for the study is justified by the fact that the educational program of this lyceum is formed taking into account the psychological and pedagogical features of the student development aged 12-16 years old, focusing on independent cognitive search, setting educational goals, independent summative and formative assessment, initiative in the educational cooperation; development of reflection at every age level, which resonates with the idea of visible learning. The participants in the study were 24 seven graders. The choice of the cohort of subjects is justified by the fact that it is in adolescence that voluntary self-regulation is formed - the conscious control of one's behaviour and activities aimed at achieving the set goals, the ability to overcome difficulties and obstacles (Klyueva \& Gensetskaya, 2017).

The following research methods were selected: examination and generalization of pedagogical experience, which helped to consider possible ways of providing feedback on homework in Mathematics; the analysis of student artefacts with subsequent statistical processing. The latter made it possible to study the dynamics of students' knowledge of Mathematics and to judge the effectiveness of feedback on homework; questionnaire of students, which made it possible to judge how the introduced didactic conditions contributed to the organization of visible learning.

In the scientific research methodology, various models of pedagogical experiment are proposed (Lazarev, 2016). This study uses an experimental design with one group, pre-test and post-test. The experiment algorithm included the following stages:

- the experimental group is assessed prior to the formative experiment;

- the developed mechanism for providing feedback is being implemented;

- the effectiveness of the feedback of the proposed feedback mechanism is tested.

The summative assessment of the experiment was aimed at identifying the level of students' knowledge in Mathematics. Teaching and learning during this period were structured in a traditional way. Feedback on selfstudy at home was not collected. The formative assessment of the experiment involved testing the developed digital feedback mechanism for homework in Mathematics. At the control stage of the experiment, the effectiveness of the proposed digital feedback mechanism for homework in Mathematics was assessed.

\section{RESULTS}

Students' performance rating at the summative assessment stage was assigned upon the test on the 'Numerical expressions and variable expressions' and "Monomial and its standard form" (Feoktistov, 2009). Taking into account the complexity of the tasks, a 100point grading system was developed for each work, which was presented to the students. As the results of the summative assessment of the experiment, the average scores of the students based on the results of these tests were used.

The results of students' performance obtained in the process of testing at the summative assessment stage of the experiment are presented at five levels in percentage terms in the form of a diagram (Figure 1). The conversion to marks was carried out according to the work program as follows: $86-100$ points - mark " 5 "; 71-85 points - mark “4"; 50-70 points - mark “3"; <50 points - mark “2"; not completed correctly no task or work not handed over mark "1".

The diagram shows that marks " 4 " and " 5 " were received by only $42 \%$ of the students (10 people), mark " 3 " $-46 \%$ of the students ( 11 people), mark " 2 " $-12 \%$ of the students ( 3 people). The average score for the test was: 65.5 out of 100 . 


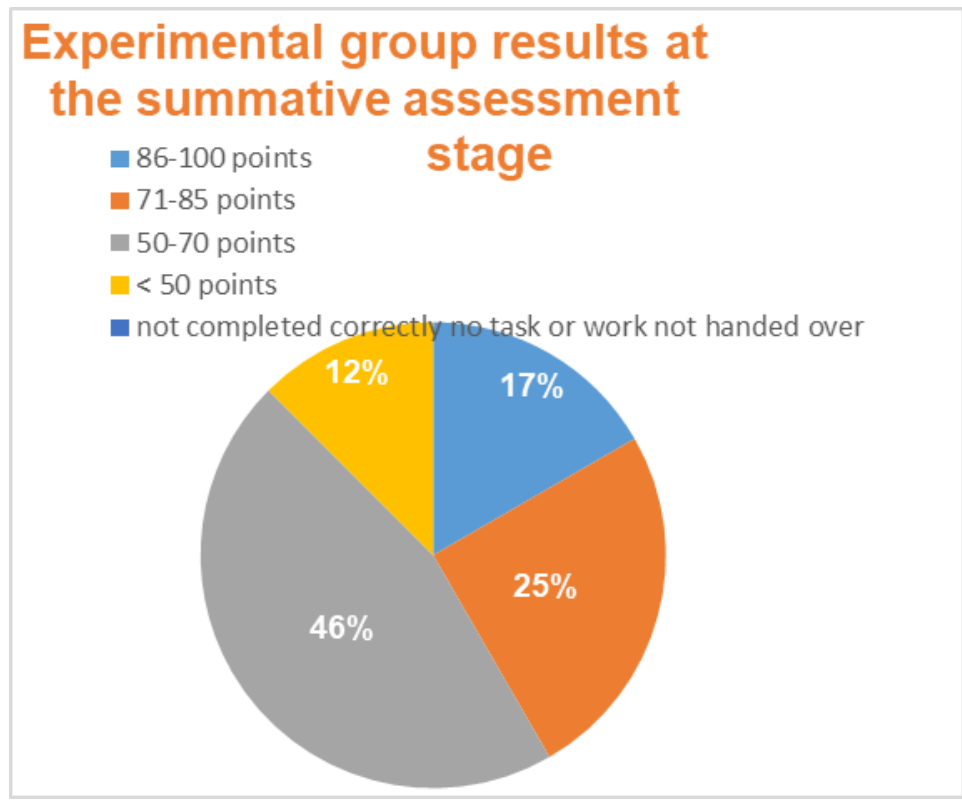

Figure 1. The level of knowledge of students at the summative assessment stage of the experiment

Table 1. Teacher feedback scheme

\begin{tabular}{|c|c|c|}
\hline What am I striving for? & Am I doing well? & What is the next step? \\
\hline Lesson objective & $\begin{array}{l}\text { Your work is very convincing! / Great job! / Tasks } \\
\text { No. ... performed correctly / accurately / without a } \\
\text { single mistake. / You have successfully coped with } \\
\text { tasks No. ... } \\
\text { Be more attentive in tasks No. ... / However, in tasks } \\
\text { No. ... there are inaccuracies, errors }\end{array}$ & $\begin{array}{l}\text { Find a mistake in problems No. ... } \\
\text { Doublecheck the calculations in problem No. } \\
\ldots \\
\text { Read the problem question carefully ... } \\
\text { In order to ..., you need to revisit the rule / } \\
\text { properties / ... on page of the textbook. }\end{array}$ \\
\hline
\end{tabular}

Thus, we can conclude that the percentage of the students whose level of knowledge corresponds to marks " 4 " and " 5 " is not high and is only $42 \%$, unfortunately, the students with a mark " 3 " prevail.

To solve this problem, we, first of all, identified the following possible ways of providing feedback on homework using digital technologies:

- a questionnaire through special test forms (for example, Microsoft Forms, Google Forms, WEBanketa, Menti.com);

- ready-made templates and constructors of interactive tasks where you can place your questions and tests (for example, LearningApps, ClassTools);

- educational platforms and services that have a library of ready-made assignments on various topics (for example, Yandex.Uchebnik, Yaklass, Moscow Electronic School);

- messaging system (through various messengers, e-mail, platforms, for example, Microsoft Teams).

The first three methods provide automatic feedback, in the latter case, the feedback is provided by the teacher. Moreover, in the first three methods, the feedback is aimed at the result of the activity, i.e., it indicates whether the work has been done correctly or not, detects errors, but does not allow the student to get answers to all the feedback questions at once: 'What am I striving for? Am I doing well? What is the next step?'. In addition, the focus of the first three methods on the result does not allow the teacher to see the very process of teaching Mathematics, they do not see which step in the process of solving a particular problem causes difficulty for the child. It turns out that the teacher does not have a clear picture of how much students consciously perceive information and how much they understand the educational actions they performed, and, therefore, in the future, the teacher does not direct their efforts to eliminate the difficulties that schoolchildren face.

In addition, many platforms have inconvenient input of mathematical expressions. Based on the abovementioned, the most optimal way to provide feedback on homework in Mathematics, in our opinion, is the messaging system. The experiment used the Microsoft Teams platform for messaging while doing homework.

Following the effective feedback model proposed by Hattie (2017) and the recommendations on how to give effective feedback (Korenev, 2020), we have developed a scheme for providing feedback by the teacher (Table 1).

This diagram is a working practice-oriented tool for the teacher. The unique character of this scheme involves the fact that it covers all feedback issues and allows the student to see their progress and mistakes completing the assignment, and most importantly, it gives recommendations for further actions. 


\begin{tabular}{|c|c|}
\hline \multicolumn{2}{|r|}{ Chapter 3. Polynomials } \\
\hline \multicolumn{2}{|r|}{$\S 5$. Polynomial and its standard form } \\
\hline $\begin{array}{l}\text { Polynomial. Calculation of } \\
\text { polynomial values (p. 11) } \\
(9.11 .2020)\end{array}$ & $\begin{array}{l}\checkmark \text { Know the definition of a polynomial. } \\
\checkmark \text { Be able to extract polynomials from various expressions. } \\
\checkmark \text { Be able to calculate the value of a polynomial with one or two variables. }\end{array}$ \\
\hline $\begin{array}{l}\text { Standard polynomial form } \\
\text { (p. 12) (11.11.2020) }\end{array}$ & $\begin{array}{l}\checkmark \text { Understand the terms "similar terms of a polynomial","reduction of similar terms", "polynomial } \\
\text { of the standard form", know the definition of the degree of a polynomial. } \\
\checkmark \text { Be able to bring a polynomial to a standard form and determine the degree of a polynomial. } \\
\checkmark \text { Know the definition of a polynomial with one variable and related terms - "leading coefficient", } \\
\text { "free coefficient", "zero-polynomial". } \\
\checkmark \text { Be able to apply the definition of equal polynomials. }\end{array}$ \\
\hline & [6 Test (\$ 5) (16.11.2020) \\
\hline
\end{tabular}

Figure 2. Roadmap on the topic 'The polynomial and its standard form'

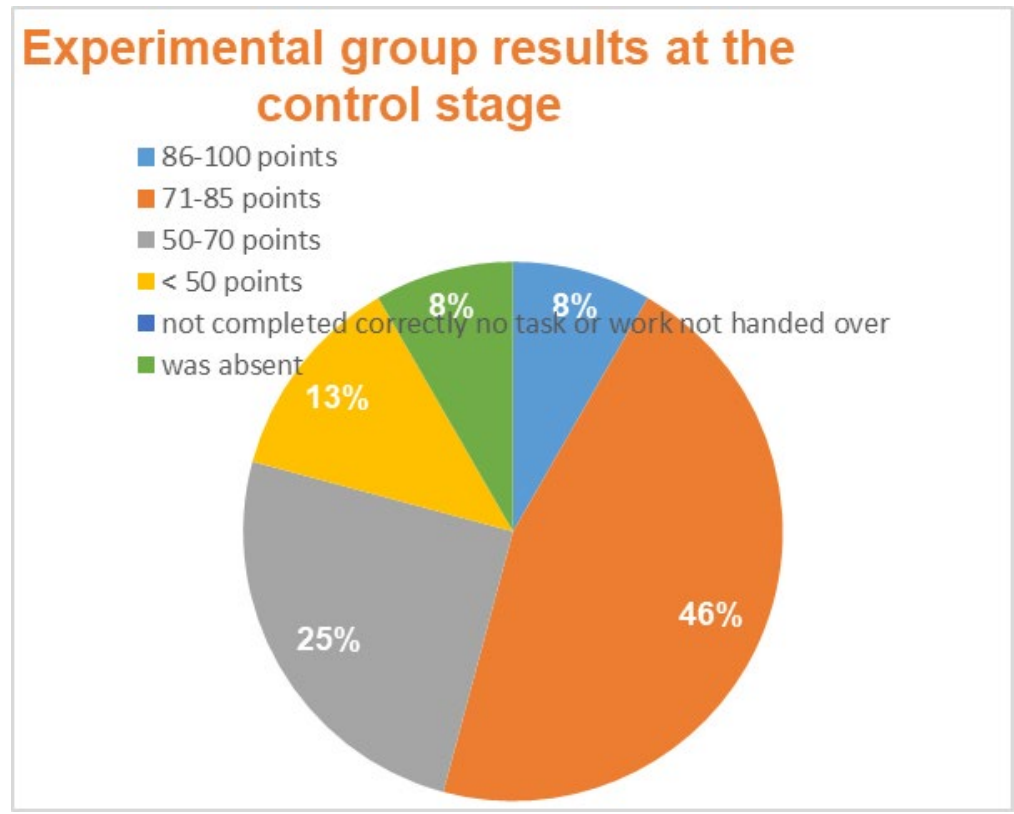

Figure 3. The level of student knowledge at the control stage of the experiment

At the summative assessment stage of the experiment, five lessons were conducted on the topic 'The polynomial and its standard form'. The educational process was carried out with the feedback which informed the students of the learning objectives, learning process and further actions.

Given the idea of visible learning, the students received a learning roadmap (Figure 2). It included the titles of chapters, paragraphs, topics, lesson objectives, and benchmarks for testing. Referring to this map during the lesson, the teacher focused the students' attention on the purpose of the lesson, thus the answer to the question: 'What are we striving for?' was given.

Feedback on homework was carried out as follows: upon completing their homework in Mathematics, the students took pictures of it and sent it to the teacher in private messages in Microsoft Teams. After checking the work, the teacher provided feedback according to the developed scheme (Table 1). This allowed the learners to get answers to two other feedback questions, 'Am I doing well?' and 'What's the next step?'. After receiving feedback, most of the students voluntarily sent the corrected work again to the teacher. Also, after analyzing the work of students that were sent to Microsoft Teams, the teacher in the next lesson focused on challenging issues and, if necessary, provided extra advice one-onone to the students who struggled to understand the material.

At the control stage of the experiment, to assess the effectiveness of the developed digital feedback mechanism for homework in Mathematics, students' progress was monitored in the form of a test on the topic: 'The polynomial and its standard form' (Feoktistov, 2009). Taking into account the complexity of the tasks, a 100-point grading system was developed. The assessment criteria were presented to the students. The results of the students' performance at the control stage of the experiment are presented at six levels in percentage terms in the form of a diagram (Figure 3). The conversion to marks was carried out in the same way.

$54 \%$ of students (13 people) received marks " 4 " and " 5 ", mark " 3 " - $25 \%$ of students ( 6 people), mark " 2 " - 
Table 2. Scale for assessing educational outcomes (by Hattie)

\begin{tabular}{ccc}
\hline Small effect size & Average effect size & High effect size \\
\hline 0.2 & 0.4 & 0.6 \\
\hline
\end{tabular}

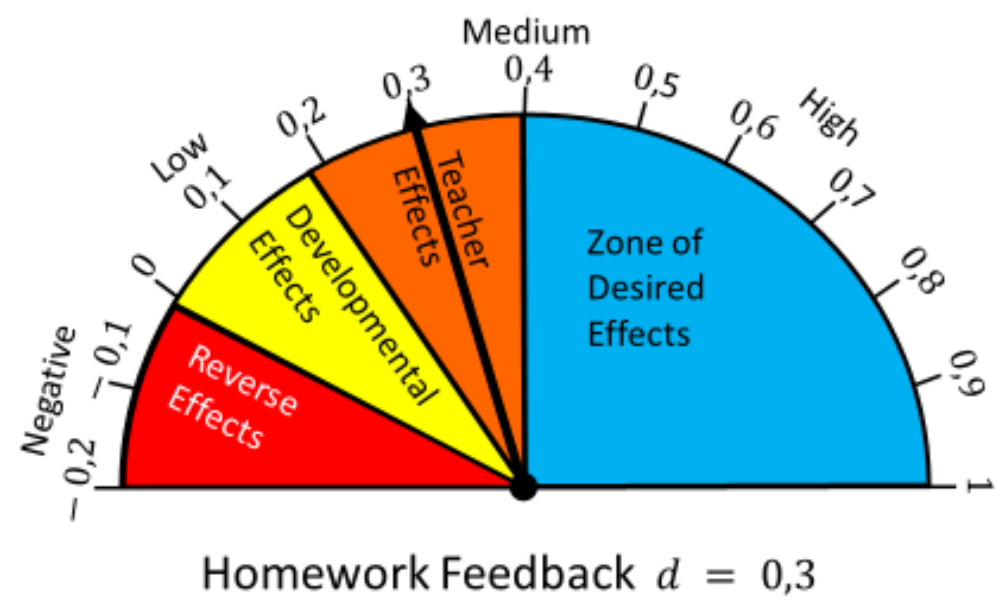

Figure 4. Barometer of Influence (Homework Feedback)

$12 \%$ of students ( 3 people), 2 persons was absent from the test. The average score for the work was 70.1 out of 100.

Comparing the results obtained with the results of monitoring the student knowledge at the summative assessment stage of the experiment, we can conclude that the percentage of students whose performance corresponds to marks " 4 " and " 5 " increased from 42 to 54 , the percentage of students with a mark " 3 " decreased from $46 \%$ to $25 \%$, the number of students with mark " 2 " remained the same. These results are due to the fact that many students improved their results from grade " 3 " to "4".

To calculate the size of the effect of feedback on homework, d, on learning success, the following formula was used:

$$
d=\frac{\text { final value }- \text { starting value }}{S D}
$$

where SD is pooled standard deviation.

In our case, the final GPA is 70.1, the initial GPA is $65.5, S D \approx 15,67$. Calculate the size of effect

$$
d=\frac{70,1-65,5}{15,67} \approx 0.3
$$

To interpret the resulting effect size, the following scale for assessing educational outcomes proposed by Hattie (2017) was used (Table 2).

Thus, the obtained effect size of feedback on homework $(\mathrm{d} \approx 0,3)$ is between the small and average effect size.

The effect size is clearly depicted on the barometer of Influence adopted in the work of Hattie 'Visible Learning' (Figure 4).

Thus, the bilateral feedback on homework in Mathematics, carried out using the proposed mechanism, has a positive effect on schoolchildren performance.

To find out to what extent the introduced didactic conditions contributed to visible learning, a questionnaire was circulated among the research participants. The questionnaire included the following questions:

1. Were the teacher's comments on homework helpful in achieving your learning goals?

2. Does the Roadmap serve as a guideline for your learning (i.e., do you see what you are learning)?

3. Do the assessment criteria help you to see what you got the grade for?

For each question of the questionnaire, four possible answers were suggested: Yes / Rather yes / Rather no / No.

22 students took part in the questionnaire. The results of the questionnaire are presented in the diagrams below (Figures 5-7).

The results of the questionnaire give us the ground to conclude that receiving feedback on homework, criteria for testing, as well as roadmaps for studying the material, contribute to establishing visible learning for students.

\section{DISCUSSIONS}

According to modern research, the educational achievements of students largely depend on the quantity and quality of feedback. Therefore, it becomes urgent to search for such feedback mechanisms that would make learning and teaching visible. Since the problem of organizing feedback on homework in Mathematics has not been studied in the literature, our research was aimed at developing didactic conditions that provide this kind of feedback. 


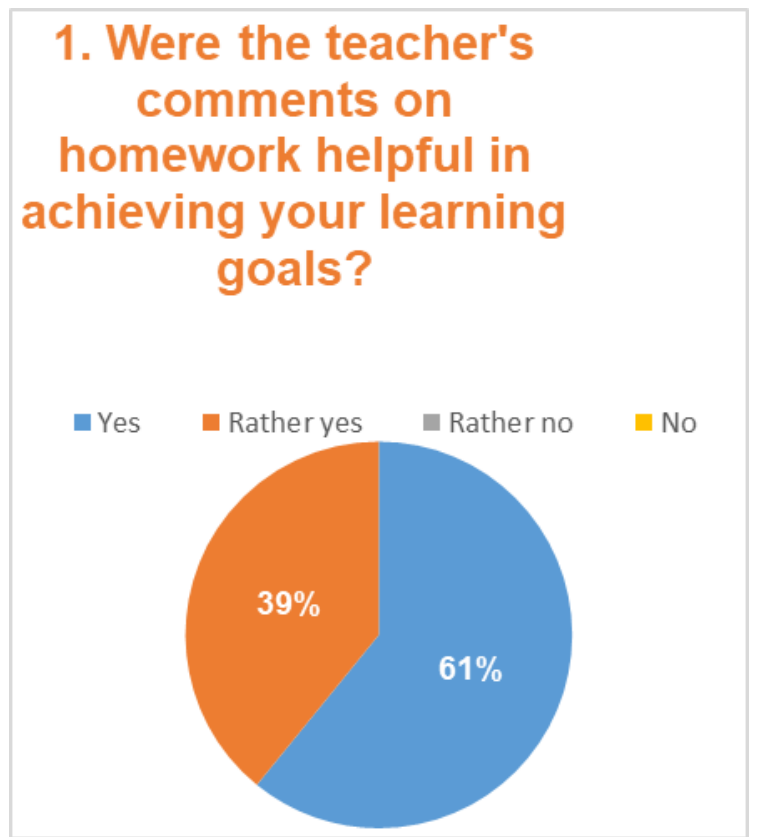

Figure 5. Students' opinion on the benefits of providing feedback on homework

\section{Does the Roadmap serve as a guideline for your learning (that is, do you see what you are learning)?}

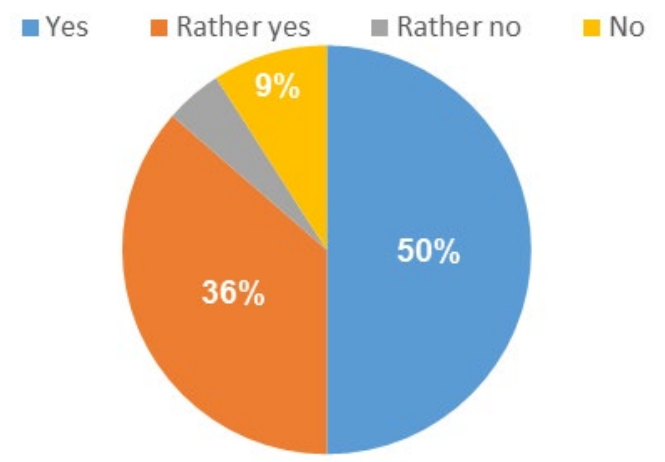

Figure 6. Students' opinion on the effectiveness of the roadmap

The study tested a bilateral feedback mechanism for Maths homework through messaging on the Microsoft Teams platform. According to the results of the study, the size of the influence effect of meaningful bilateral homework feedback on student performance was $d=$ 0,3 . The resulting effect size is halfway between the small and medium effect sizes on the scale for assessing educational outcomes proposed by J. Hattie (2017). Thus, the data of experimental verification confirm that providing a bilateral nature of feedback in the course of

\section{Do the assessment criteria help you to see what the grade is for?}

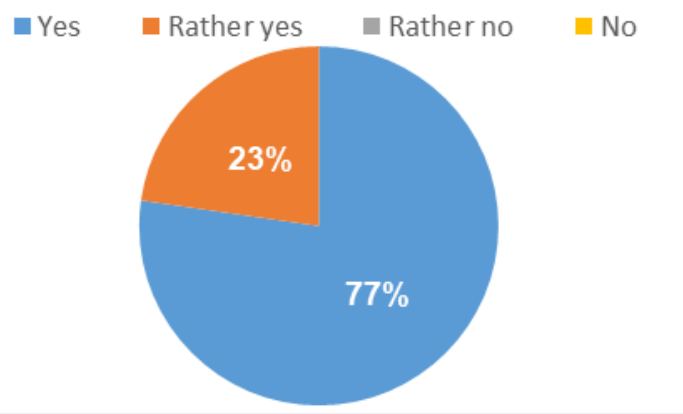

Figure 7. Students' opinion on the effectiveness of assessment criteria for testing

self-directed homework using digital technologies contributes to the achievement of higher educational outcomes by students.

However, in the study by J. Hattie (2017), the size of the feedback effect obtained on the materials of a foreign school is slightly higher than that obtained in this study, namely: feedback $-d=0.73$; specific feedback forms: recurring testing $-d=0.34$ test preparation and coaching $-d=0.22$ formative assessment $d=0.9$, survey $-d=0.46$. In our opinion, these differences are primarily due to the relatively little use of the proposed feedback mechanism in the educational process. In addition, the proposed feedback mechanism is carried out through digital technologies in a remote format, which also requires longer adaptation on the part of students and teachers.

However, this study further confirms that the quality, frequency and promptness of feedback can increase the effectiveness of teaching and learning.

\section{CONCLUSION}

Summing up the results of the study, the following conclusions can be drawn:

1. Various digital technologies: test forms; various templates and constructors of interactive assignments where the teacher can place their questions and tests; educational platforms and services with a library of ready-made assignments on various topics; messaging systems allow you to provide feedback on your Maths homework. However, in the first three cases, the feedback is automatic and is often aimed only at the result of the activity; in the latter case, it is provided by the teacher, which makes it meaningful. In this case, the feedback helps develop and promote and is carried out at the procedural level, i.e. it helps the student not only understand what their result is at the given moment but 
also understand what progress they are making in learning and what needs to be done to achieve the established goal.

2. In order to make teaching visible and learning to be an explicit goal, students may be presented with a roadmap that includes titles of chapters, paragraphs, topics, goals to be achieved upon the end of the study, as well as guidelines for testing.

3. The effect size of the influence of meaningful bilateral feedback on homework on learning progress is 0.3. The resulting effect size is halfway between the small and medium effect sizes on the scale for assessing educational outcomes proposed by Hattie (2017).

Thus, the developed didactic conditions, which provide a bilateral nature of feedback on self-directed homework using digital technologies, contribute to an increase in the effectiveness of the educational process and the organization of visible learning.

\section{LIMITATIONS}

As the study showed, the organization of bilateral feedback on homework in Mathematics, carried out using the proposed mechanism, has a positive effect on the success of schoolchildren's learning and the organization of visible learning. However, providing feedback using the proposed mechanism requires a lot of time from the teacher, since all feedback is provided by the teacher himself and is of a selective, individual nature. Nevertheless, at this stage of development of modern education, this mechanism is the only way to provide meaningful feedback, which is aimed not at the result of activity, but at the process of mastering the necessary actions by students to achieve the educational goal. An urgent issue is the establishment of automated feedback, which would also be aimed at the learning process and, with the answer to all the feedback questions, would form the learning trajectory of each student.

Author contributions: All authors have sufficiently contributed to the study, and agreed with the results and conclusions.

Funding: This paper has been supported by the Kazan Federal University Strategic Academic Leadership Program.

Declaration of interest: No conflict of interest is declared by authors.

\section{REFERENCES}

Azizi, M., Kralik, R., Petrikovicova, L., \& Tkáčova, H. (2020). A comparative study of the effects of selfassessment and peer feedback on literature students' oral production. Science for Education Today, 10(5), 7-27. https://doi.org/10.15293/26586762.2005.01

Baisalbaeva, M. K., \& Syzdykova, G. S. (2019). Principles of constructive feedback in research practice of an international baccalaureate teacher. Young Scientist, 6, 198-201.
Begishev, I., Khisamova, Z., \& Vasyukov, V. (2021). From robotics technology to environmental crimes involving robots. E3S Web of Conferences, 244, 12029. https://doi.org/10.1051/e3sconf/202124412029

Federal State Educational Standard for Compulsory Education. (2010). Garant: Information and legal support. https://base.garant.ru/55170507/53f8942 1bbdaf741eb2d1ecc4ddb4c33/

Feoktistov, I. E. (2009). Algebra. 7th grade. Didactic materials. Guidelines. Mnemosina.

Gin, A. A. (2016). Methods of pedagogical technique: freedom of choice, openness, activity, feedback, ideality: A manual for a teacher. VITA-PRESS.

Hattie, J. (2017). Visible learning. Publishing house "National Education". https://doi.org/10.4324/ 9781315206387-11

Hu, B. Y., Li, Y. H., Zhang, X., Roberts, S. K., \& Vitiello, G. (2021). The quality of teacher feedback matters: Examining Chinese teachers' use of feedback strategies in preschool math lessons. Teaching and Teacher Education, 98, 103253. https:/ / doi.org/10.1016/j.tate.2020.103253

Ibragimov, G. I. (2017). Purpose as a pedagogical category. In Innovation in vocational and vocational teacher education (pp. 68-72).

Klyueva, T. N., \& Gensetskaya, Yu. V. (2017). Formation of conscious self-regulation of adolescents in educational activities: guidelines. GBU DPO "Regional Sociopsychological Center".

Korenev, A. A. (2018). Feedback in teaching and pedagogical communication. Rhema. Rem, 2, 112127.

Korenev, A. A. (2020). How to give effective feedback? https:/ / teacher.yandex.ru/posts/kak-davateffektivnuyu-obratnuyu-svyaz

Korotkova, A. Yu., \& Litvinovskaya, N. Yu. (2019). Feedback in the classroom as an element of the formative assessment system. Implementation of educational and educational functions of a modern elementary school: Collection of articles based on the materials of the X All-Russian Scientific and Practical Conference (pp. 122-126). Federal State Budgetary Educational Institution of Higher Education "Perm State Humanitarian Pedagogical University".

Larionova, A. A., Zaitseva, N. A., Anoshina, Y. F., Gaidarenko, L. V., \& Ostroukhov, V. M. (2018). The modern paradigm of transforming the vocational education system. Astra Salvensis, 6, 436-448.

Lazarev, V. S. (2016). On the problem of ensuring the validity of a pedagogical experiment. Bulletin of the Russian Academy of Education, 2, 50-64.

Monteiro, V., Mata, L., Santos, N., Sanches, C., \& Gomes, M. (2019). Classroom talk: The ubiquity of 
feedback. Frontiers in Education, 4, 140. https://doi.org/10.3389/feduc.2019.00140

Myshkovskaya, A. P. (2016). Use of effective feedback techniques, mutual control and mutual evaluation in physics lessons. https://multiurok.ru/blog/ispolzovaniie-effiektivnykh-priiemov-obratnoi-sviazivzaimokontrolia-i-vzaimootsienki-uchashchikhsiana-urokakh-fiziki.html

Razumovskaya, M., Zaitseva, N. A., Larionova, A. A., Chudnovskiy, A. D., \& Breusova, E. A. (2018). Prospects for applying various forms of organizational integration to improve the quality of education. Astra Salvensis, 6, 348-362.

Roslan, R., Panjang, S. M., Yusof, N., \& Shahrill, M. (2018). Teacher's feedback in teaching science in a bilingual Bruneian primary classroom. On the
Horizon. https://doi.org/10.1108/OTH-09-20170080

Salomasov, V. (2011). Principles of effective feedback. https://orator.biz/library/communication/princi pi_obratniy_svyazi/

Wang, W., \& Li, S. (2021). Corrective feedback and learner uptake in American ESL and Chinese EFL classrooms: A comparative study. Language, Culture and Curriculum, 34(1), 35-50. https://doi.org/ 10.1080/07908318.2020.1767124

Zaitseva, N. A., Larionova, A. A., Filatov, V. V., Rodina, E. E., Zhenzhebir, V. N., Povorina, E. V., \& Palastina, I. P. (2018). Natural-resource potential management of region's territorial ecosystems. Ekoloji, 27(106), 495-502.

\section{http://www.ejmste.com}

